\title{
EXPONENTIAL DICHOTOMY OF LINEAR AUTONOMOUS SYSTEMS OVER TIME SCALES
}

\section{Akbar Zada, TongXing Li, SAMreen Ismail And OMAR ShaH}

Abstract. In this paper we study the exponential stability and exponential dichotomy of the first order linear dynamic equation $z^{\Delta}(s)=M z(s)$ in terms of the boundedness of solutions of the following Cauchy problems:

$$
\left\{\begin{array}{l}
z^{\Delta}(s)=M z(s)+f(s) Q b, 0 \leqslant s \in \mathbb{T}, \\
z(0)=0
\end{array}\right.
$$

and

$$
\left\{\begin{array}{l}
w^{\Delta}(s)=-M w^{\sigma}+f(s)(I-Q) b, \\
w(0)=0,
\end{array}\right.
$$

where $\mathbb{T}$ is a time scale, $M$ is a regressive matrix, $b$ is a non-zero vector in $\mathbb{C}^{m}, f(s)$ is a bounded and right-dense continuous function on $\mathbb{T}$, and $Q$ is a projection on $\mathbb{C}^{m}$.

Mathematics subject classification (2010): 34D09, 34N05, 34D05.

Keywords and phrases: exponential stability, Cauchy problem, first order linear dynamic equation, time scale.

\section{REFERENCES}

[1] N. Ahmad, H. Khalid, and A. Zada, Uniform exponential stability of discrete semigroup and space of asymptotically almost periodic sequences, Zeitschrift fur Analysis und ihre Anwendungen: Journal for Analysis and its Applications, 34 (2015), 477-484.

[2] S. Balint, On the Perron-Bellman theorem for systems with constant coefficients, Ann. Univ. Timisoara, 21, fasc, 1-2 (1983), 3-8.

[3] M. Bohner and A. Peterson, Dynamic Equations on Time Scales: An Introduction with Applications, Birkhäuser, Boston, Mass, USA, 2001.

[4] M. Bohner and A. Peterson, Advances in Dynamics Equations on Time scales, Birkhäuser, Boston, 2003.

[5] E. Braverman and B. Karpuz, Uniform exponential stability of first-order dynamic equations with several delays, Applied Mathematics and Computation, 218 (2012), 10468-10485.

[6] C. Buşe, On the Perron-Bellman theorem for evolutionary processes with exponential growth in Banach spaces, New Zealand Journal of Mathematics, 27 (1998), 183-190.

[7] C. Buşe and D. Barbu, Some remarks about the Perron condition for strongly continious semigroups, Analele Univ. Timisora, fasc, 1, (1997).

[8] C. Buşe and M. Reghiş, On the Perron-Bellman theorem for strongly continious semigroups and periodic evolutionary processes in Banach spaces, Italian journal of Pure and Applied Mathematics, 4 (1998), 155-166.

[9] C. Buşe and A. Zada, Dichotomy and boundedness of solutions for some discrete Cauchy problems, Operator Theory: Advances and Applications, 203 (2010), 165-174.

[10] S.K. Choi, N.J. Koo, and D.M. Im, h-Stability of linear dynamics equations on time scales, J. Math. Anal. Appl., 324 (2006), 707-720.

[11] J.J. Dachunha, Stability for time varying linear dynamic systems on time scales, J. Comput. Appl. Math., 176 (2005), 381-410. 
[12] Ju.L. Daletckii and M.G. Krein, Stability of Solutions of Differential Equations in Banach Spaces, Amm. Math. Soc. Providence, RI, (1974).

[13] T.S. Doan, A. Kalauch, and S. Siegmund, Exponential stability of linear time-invariant systems on time scales, Nonlinear Dyanamics and Systems Theorey, 9 (2009), 37-50.

[14] N.H. Du and L.H. Tien, On the exponential stability of dynamic equations on time scales, J. Math. Anal. Appl., 331 (2007), 1159-1174.

[15] T. Gard and J. Hoffacker, Asymptotic behavior of natural growth on time scales, Dynam. Systems Appl., 12 (2003), 131-147.

[16] G. Greiner, J. Voight, and M. Wolff, On the spectral bound of the generator of semigroups of positive operators, Journal of Operator Theory, 10 (1981), 87-94.

[17] A.E. Hamza and K.M. Oraby, Stability of abstract dynamic equations on time scales, Advances in Difference Equations, 2012 (2012), 1-15.

[18] S. Hilger, Ein Maskettenkalkül mit Anwendung auf Zentrumsmannigfaltigkeiten, $\mathrm{PhD}$ thesis, Univ. Würzburg, (1988).

[19] S. Hilger, Analysis on measure chains - a unified approach to continuous and discrete calculus, Results Math., 18 (1990), 18-56.

[20] J. Hoffacker and C.C. Tisdell, Stability and instability for dynamic equations on time scales, Comput. Math. Appl., 49 (2005), 1327-1334.

[21] M.G. Krein, On some questions related to the ideas of Lyapunov in the theory of stability, Uspeckhi Mat. Nauk, 3 (1948), 166-169, [in Russian].

[22] V. Lupulescu and A. Zada, Linear impulsive dynamic systems on time scales, Electronic Journal of Qualitative Theory of Differential Equations, 2010 (2010), 1-30.

[23] J.M.A.M. van Neerven, The Asymptotic Behaviour of Semigroups of Linear Operators, Birkhäuser, Basel, (1996).

[24] J.M.A.M. van Neerven, Individual stability of strongly continuous semigroups with uniformly bounded local resolvent, Semigroup Forum, 53 (1996), 155-161.

[25] A.C. Peterson and N.Y. Raffoul, Exponential stability of dynamic equations on time scales, Adv. Difference Equ., 2 (2005), 133-144.

[26] C. Pötzsche, Exponential dichotomies of linear dynamic equations on measure chains under slowly varing coefficients, J. Math. Anal. Appl., 289 (2004), 317-335.

[27] C. Pötzsche, S. Siegmund, and F. Wirth, A spectral characterization of exponential stability for liner time-invariant systems on time scales, Discrete Contin. Dyn. Syst., 9 (2003), 1223-1241.

[28] A. Zada, A characterization of dichotomy in terms of boundedness of solutions for some Cauchy problems, Electronic Journal of Differential Equations, 2008 (2008), 1-5.

[29] A. Zada, M. Arif, and H. Khalid, Asymptotic behavior of linear and almost periodic discrete evolution systems on Banach space $\mathscr{A} \mathscr{A} \mathscr{P}_{0}^{r}\left(\mathbb{Z}_{+}, X\right)$, Qual. Theory Dyn. Syst., doi: 10.1007/s12346-015-01775 .

[30] A. Zada, N. Ahmad, I.U. Khan, and F.M. Khan, On the exponential stability of discrete semigroups, Qual. Theory Dyn. Syst., 14 (2015), 149-155.

[31] A. Zafer, Calculating the matrix exponential of a constant matrix on time scales, Appl. Math. Lett., 21 (2008), 612-616. 